\title{
Peningkatan Sistem Motorik Anak Usia Prasekolah melalui kegiatan Outbound di KB Aisyiyah Jonggrangan, Klaten
}

\author{
Puspita Indra Wardhani ${ }^{1}$, Ardi Ade Sarjono ${ }^{2}$, Faricha Sarah Prahesti ${ }^{3}$, Femilla Aphrodite Wido \\ Hajandi $^{4}$, Wiwik Ariesta ${ }^{5}$, Juanda Ardiansyah ${ }^{6}$, Hanik Noviyanti ${ }^{7}$, Rizka Arti Nurdeni ${ }^{8}$, Yulli \\ Listiawati $^{9}$ \\ ${ }_{1,2,3,4,5,6,7,8,9}$ Fakultas Keguruan dan Ilmu Pendidikan, Universitas Muhammadiyah Surakarta, \\ Indonesia
}

\section{INFORMASI ARTIKEL}

\section{Histori Artikel:}

Submit: 27 April 2020

Revisi: 2 Mei 2020

Diterima: 4 Mei 2020

Publikasi: 6 Mei 2020

Periode Terbit: Desember 2019

\section{Kata Kunci:}

motorik,

outbound,

permainan,

usia prasekolah

\section{Correspondent Author:}

Ardi Ade Sarjono

Fakultas Keguruan dan Ilmu Pendidikan

Universitas Muhammadiyah Surakarta,

Indonesia

Email: adeardi00@gmail.com

\begin{abstract}
ABSTRAK
Masa prasekolah termasuk masa-masa bermain untuk anak. Belajar sambil bermain pun dapat berpengaruh terhadap perkembangan sistem motorik anak, terutama pada anak usia prasekolah. Maka, dibuatlah metode pembelajaran yang menarik agar anak merasa senang dan semangat untuk belajar, yaitu metode Outbound. Selain dapat meningkatkan sistem motorik anak, metode ini dibuat untuk mengenalkan anak pada lingkungan sekitar. Pengabdian ini bertujuan memaparkan dampak atau pengaruh adanya kegiatan Outbound dan cara mengembangkan sistem motorik melalui permainan di dalam Outbound. Hasil pengabdian menunjukkan bahwa adanya permainan dalam kegiatan Outbound yang dilakukan KB Aisyiyah Jonggrangan, Klaten Utara memberikan pengaruh yang signifikan terhadap hasil belajar dan perkembangan sistem motorik anak. Pengabdian ini penting dilakukan sebagai bentuk upaya yang dapat dilakukan dalam pengembangan metode pembelajaran, karena pada dasarnya pembelajaran bisa dilakukan di mana saja, baik di dalam maupun di luar ruangan atau alam terbuka.
\end{abstract}

\section{Pendahuluan}

Berbicara mengenai sistem motorik sangat identik dengan tumbuh kembang anak. Perkembangan motorik merupakan proses tumbuh kembang gerak pada anak. Perkembangan ini biasanya ditandai dengan gerak baru yang dilakukan oleh anak. Pada dasarnya setiap anak mempunyai perkembangan motorik yang berbeda-beda. Hal ini, dikarenakan anak memiliki kematangan saraf dan otot yang berbeda antara anak satu dengan yang lainnya. Dengan demikian, untuk membuat anak semakin kuat dan lincah diperlukan pengembangan agar tumbuh kembang anak terjadi secara optimal.

Usia prasekolah merupakan masa-masa bermain bagi anak. Permainan tentu menjadi hal yang sangat penting bagi anak. Permainan merupakan bentuk aktivitas yang menyenangkan semata-mata untuk melakukan aktivitas atau kegiatan itu sendiri. Terlepas dari itu, dalam sebuah permainan yang diikuti dapat membantu perkembangan anak, baik segi fisik, moral, sosial, intelektual, maupun emosional. 
Hal tersebut diperkuat dengan paparan (Kusumaningtyas, 2016) bahwa dalam mendidik anak pada usia dini, diperlukan adanya bekal pemahaman yang cukup mengenai dunia anak dan proses perkembangannya.

Kegiatan untuk mengembangkan sistem motorik pada anak dilakukan pada tahap usia sedini mungkin. Usia 0-6 tahun perkembangan anak merupakan usia emas dalam mempelajari sesuatu karena pada usia ini anak memiliki kemampuan belajar yang pesat (Pang \& Fong, 2009; Zeng, dkk., 2017). Anak-anak mulai dikenalkan dengan kegiatan-kegiatan bermain yang menyenangkan. Kegiatan yang menyenangkan dan melibatkan bergeraknya anggota tubuh.

Pengenalan kegiatan fisik digunakan untuk merangsang perkembangan motorik pada anak. Perkembangan motorik berpengaruh pada perkembangan anak lainnya seperti kogitif, sosial dan emosional (Aye, dkk., 2017; Hernandez \& Cacola, 2015). Perkembangan motorik ditandai melalui kontrol gerakan tubuh melalui gerakan terkoordinasi antara sistem saraf, otot, otak dan sum-sum tulang belakang (Hasnida, 2014). Oleh karena itu pengembangan motorik anak dilakukan sejak usia dini.

Sekarang ini semakin merebak bentukbentuk aktivitas fisik atau olahraga populer di kalangan masyarakat luas, contohnya kegiatan atau aktivitas di luar kelas maupun di alam terbuka atau yang sering disebut Outbound. Secara umum, adanya kegiatan Outbound diharapkan dapat terciptanya suasana keakraban, kebersamaan serta kerjasama tim, yang nantinya akan bermanfaat dalam mengatasi permasalahan yang lebih besar. Di Indonesia sendiri, kegiatan Outbound tidak hanya berkembang di sekolah-sekolah, melainkan di berbagai tingkatan, seperti pengusaha, pekerja kantor, pegawai negeri, karena pada dasarnya kegiatan ini bertujuan memperoleh kesenangan mental atau jiwa.

Pada perkembangannya, anak mengalami beberapa tahap perkembangan. Demi tercipta utuhnya perkembangan anak, maka kegiatan yang sifatnya membangun sangat diperlukan. Salah satu kegiatan yang dapat dilakukan, yaitu kegiatan Outbound. Berbagai pihak meyakini bahwa penggunaan metode Outbound dapat memberikan kontribusi positif terhadap kesuksesan hasil belajar.

Pada dasarnya metode Outbound dilaksanakan dalam kegiatan pembelajaran melalui pengalaman (experiential learning) yang disajikan dalam berbagai bentuk permainan (Akin, 2015). Selanjutnya, Danuminarto dan Santosa dalam (Akin, 2015) menyatakan bahwa "Experiential learning adalah suatu bentuk dukungan konkret terhadap hubungan teori dengan praktik dalam dunia nyata, yang mana peserta yang terlibat dalam proses pembelajaran akan mendapatkan hasil terbaik."

Tak terkecuali KB Aisyiyah Jonggrangan Klaten Utara, Klaten. Taman kanak-kanak tersebut juga menerapkan metode Outbound sebagai salah satu kegiatan pembelajaran yang tepat dilakukan pada usia prasekolah. Outbound yang dilakukan KB Aisyiyah Jonggrangan lebih bertujuan untuk pengembangan sistem motorik anak, yakni dengan adanya pengembangan permainan-permainan yang dilakukan. Adanya permainan di dalam Outbound membuat anak merasa senang dan semangat untuk belajar.

Pengabdian terdahulu yang relevan dengan pengabdian ini adalah pengabdian (Kusmiati \& Sumarno, 2018), (Garnika \& 
Sulastri, 2017), (Widodo \& Lumintuarso, 2017), (Buchori et al., 2016), (Hakim \& Kumala, 2016), (Kusumaningtyas, 2016), (Akin, 2015), (Falah, 2014), dan (Mutmainah, 2012). Berdasarkan beberapa pengabdian relevan tersebut dapat dipaparkan bahwa kegiatan Outbound berdampak atau berpengaruh besar pada perkembangan anak.

Sekarang ini, outward bound atau Outbound yang lebih dikenal di Indonesia dimanfaatkan sebagai sebuah metode pelatihan manajemen invidu dan atau kelompok dengan media alam terbuka, yang tentunya dikemas dalam bentuk games-games interaktif yang sifatnya simulatif, berstruktur, dan ada penilaian untuk mengembangkan skill tertentu yang tujuan utamanya meningkatkan kualitas sumber daya manusia (SDM) (Falah, 2014).

Outbound merupakan metode yang dibuat untuk mengembangkan diri anak melalui kegiatan-kegiatan beraspek psikomotorik, kognitif, dan afeksi melalui pengalaman baru dalam pendekatan pembelajaran (Susanta dalam (Garnika \& Sulastri, 2017)). Adapun, menurut (Falah, 2014) Outbound adalah aktivitas pelatihan di luar ruangan ataupun alam terbuka (outdoor) yang menyenangkan dan penuh dengan tantangan. Walaupun dihadapkan dengan tantangan besar sekalipun, Outbound mampu mengembangkan kesadaran diri setiap anak.

Menurut (Sugandi, 2014), belajar selalu terkait dengan tiga area perkembangan, yaitu kognitif, afektif dan psikomotor. Konferensi Genewa tahun 1979 menyatakan bahwa aspekaspek yang perlu dikembangkan pada anak prasekolah atau usia dini, yaitu motorik, bahasa, kognitif, emosi, sosial, moralitas, dan kepribadian (Dani dalam (Mutmainah, 2012)).
Menyadari bahwa dengan belajar sambil bermain dapat berpengaruh terhadap perkembangan sistem motorik anak, maka pengabdian memilih judul "Pengembangan Permainan Outbound untuk Meningkatkan Sistem Motorik Anak Usia Prasekolah KB Aisyiyah Jonggrangan". Pengabdian ini bertujuan untuk memberikan gambaran mengenai pengaruh adanya kegiatan Outbound dan cara mengembangkan sistem motorik anak melalui permainan di dalam Outbound.

\section{Metode Pelaksanaan}

Metode dalam pengabdian ini menggunakan dua pendekatan, yaitu pendekatan teoretis dan praktik. Pertama, pendekatan teoretis, pada pendekatan ini anak dijelaskan mengenai tujuan dan manfaat diadakannya Outbound serta dikenalkan berbagai jenis permainan yang dapat dilakukan saat kegiatan Outbound, terutama permainan yang dapat meningkatkan sistem motorik mereka. Kedua, pendekatan praktik, pada pendekatan kali ini terdapat tiga aspek, di antaranya kognitif, afektif, dan psikomotor. Aspek-aspek tersebut sangat penting dan berpengaruh pada perkembangan anak-anak.

Sasaran dalam pengabdian ini adalah anak-anak usia prasekolah KB Aisyiyah Jonggrangan, Klaten Utara yang terdiri atas kelas A (kecil) dan kelas B (besar). Kegiatan ini bertujuan sebagai bentuk pelatihan dalam meningkatkan sistem motorik anak melalui permainan dalam kegiatan Outbound. Selanjutnya, waktu pengabdian pada Jumat, 21 Februari 2020. Adapun, tempat pengabdian di Lapangan Dendengan, Klaten Utara, Klaten. 


\section{Hasil Pelaksanaan dan Pembahasan}

1. Peningkatkan Sistem Motorik melalui Permainan Outbound

Kegiatan Outbound yang dapat membantu proses perkembangan anak, yaitu berupa simulasi kehidupan yang diekspresikan melalui bentuk-bentuk permainan kreatif, rekreatif dan edukatif. Permainan dalam Outbound dapat dilakukan, baik secara individual maupun kelompok dengan maksud untuk pengembangan diri (personal development) dan kelompok (team development) (Falah, 2014).

Permainan yang lucu, menarik, menyenangkan, dan berbeda membuat anak tertarik untuk mengikuti dan melakukannya. Maka, tanpa disadari, anak-anak telah melakukan permainan yang sebenarnya termasuk dalam simulasi kehidupan. Permainan tersebut secara otomatis telah mengembangkan kemampuan berpikir, menjalankan peran, dan belajar menyelesaikan permasalahan yang mereka hadapi dengan praktik secara langsung (Hakim \& Kumala, 2016).

Bermain di luar ruangan ataupun kelas penekanannya lebih kepada perkembangan motorik kasar anak, di antaranya koordinasi otot kaki, tangan maupun kelenturan badan. Selain itu, bermain di luar ruangan biasanya membutuhkan alat-alat, seperti bola dunia, tangga majemuk, tangga setengah lingkaran, papan titian, papan luncur, jembatan, jungkitan, kuda goyang, ayunan, papan loncat, bak pasir, bak air, dan papan merayap (Kusumaningtyas, 2016).

Beberapa hal yang bisa dipersiapkan dalam kegiatan pembelajaran di alam terbuka (Outbound), antara lain: (a) Menentukan seperti apa bentuk kegiatan; (b) Menentukan waktu kegiatan Outbound; (c) Mempersiapkan peralatan dan bahan yang dibutuhkan. Adapun, bagaimana pelaksanaan Outbound akan dipaparkan (Kusumaningtyas, 2016), di antaranya: (a) Siswa dibagi atas kelompokkelompok; (b) Adanya penjelasan yang diberikan Guru mengenai benda dan sifatnya yang digunakan dalam Outbound; dan (c) Adanya paparan tentang aturan permainan dalam kegiatan tersebut.

Agar motorik kasar anak dapat berkembang dengan baik, maka harus diberikan kesempatan yang baik, termasuk di dalamnya orang tua, lingkungan sekitar atau tempat tinggal, guru maupun lingkungan sekolah. Beberapa cara yang dapat dilakukan untuk mencapai perkembangan yang optimal, yaitu dengan bermain, bergerak dan membuat kreativitas dan atau menciptakan inovasi (Juliani, et al, 2020).

Selanjutnya, gerakan motorik kasar dapat dibagi menjadi dua, yakni gerakan lokomotor dan non-lokomotor. Pertama, gerakan lokomotor merupakan aktivitas memindahkan tubuh dari satu tempat ke tempat yang lain, seperti merangkak, melangkah, melompat, meloncat, berjalan, dan berlari, Kedua, gerakan nonlokomotor yaitu tindakan yang dilakukan tubuh, tetapi tidak memindahkan tubuh dari satu tempat ke tempat yang lainnya, seperti halnya bangun tidur, duduk, telungkup, menarik ke atas dan menjaga keseimbangan badan dengan papan titian (Kusumaningtyas, 2016).

Outbound yang dilakukan KB Aisyiyah Jonggrangan, Klaten Utara diselenggarakan pihak sekolah bersama mahasiswa KKN-Dik FKIP UMS). Kegiatan Outbound yang dipandu mahasiswa KKN-Dik ini merupakan bentuk kegiatan dalam melatih perkembangan motorik 
kasar anak. Kegiatan yang dapat menghidupkkan atau meningkatkan motorik kasar anak, antara lain berjalan, berlari, melempar, menendang, maupun melompat. Bentuk kegiatan tersebut dapat memacu otototot pada anak.

Selain bermanfaat membentuk kekuatan otot dan melatih fisik anak, kegiatan bermain di luar ruangan atau di alam bebas ini dapat menjadi sarana belajar yang menyenangkan, sekaligus sosialisasi dan pengenalan terhadap lingkungan sekitar. Perkembangan motorik, terutama motorik kasar pada anak perlu diperhatikan, karena pertumbuhan dan perkembangan anak mempengaruhi masa depan mereka kelak.

Outbound juga digunakan untuk melatih anak-anak untuk belajar bekerja sama (Maryatun, 2011). Bekerjasama adalah kegiatan yang dilakukan dua orang atau lebih untuk meraih tujuan tertentu. Penanaman kerjasama sedari dii perlu dilakukan untuk memupuk kepercayaan diri anak dalam bergaul dengan teman-temannya dan lingkungan sosialnya. Anak yang dapat bekerjasama dalam perkembangannya akan mudah beradaptasi terhadap perubahan yang terjadi pada lingkungannya.

Permainan Outbound yang dilakukan KB Aisyiyah Jonggrangan, yakni kegiatan melempar bola. Melempar bola pada lingkaran yang telah disediakan dengan batas start yang ditentukan. Permainan tersebut diikuti dengan antusias oleh seluruh anak didik KB Aisyiyah Jonggrangan. Awalnya, anak-anak dibagi menjadi dua kelompok 'Kelompok X dan Kelompok Y'. Masing-masing kelompok terdiri atas sembilan anak (acak antara anak-anak kelas A maupun kelas B).

\section{Pengaruh Permainan Outbound dalam Meningkatkan Sistem Motorik \\ Outbound dibagi menjadi dua, yaitu Real} Outbound dan fun Outbound. Real Outbound merupakan kegiatan yang memerlukan ketahanan dan tantangan fisik lebih, lebih berat daripada fun Outbound. Adapun, fun Outbound merupakan kegiatan yang berada di alam terbuka dan ringan, karena tidak begitu menekankan unsur fisik. Meskipun hanya melalui permainan ringan, namun terkesan menyenangkan. Selain itu, fun Outbound memiliki risiko yang lebih kecil dan banyak manfaat yang untuk pengembangan diri anak (Falah, 2014).

Kurangnya stimulasi pada anak menyebabkan perkembangan motorik anak tidak berkembang dengan semestinya. Untuk itu, anak perlu stimulus yang cukup diimbangi adanya metode yang tepat supaya anak dapat dan bisa mengembangkan aspek motorik kasar dengan lebih optimal. Paparan mengenai stimulasi juga dipaparkan oleh Soetjiningsih dalam (Mutmainah, 2012), stimulus ialah suatu hal yang sangat penting dalam proses tumbuh kembang anak, karena dengan memberikan stimulasi secara bertahap dan terus-menerus sesuai tingkat usia anak akan mengoptimalkan perkembangan anak.

Salah satu manfaat adanya pengembangan permainan dalam kegiatan Outbound adalah untuk meningkatkan sistem motorik anak, terutama motorik kasar. Senada dengan hal tersebut menurut Sari dalam (Mutmainah, 2012), saat usia prasekolah, anak mempunyai potensi besar untuk mengoptimalkan segala aspek perkembangan, termasuk di dalamnya motorik kasar. 
Kemampuan motorik kasar biasanya dikembangkan melalui gerakan-gerakan fisik yang dapat melatih fungsi otot besar secara. Selain itu, anak juga memerlukan rangsangan dari lingkungan luar individu untuk menunjang perkembangan atau membentuk motorik kasar anak.

Gerakan motorik kasar adalah suatu gerak yang dipengaruhi ketrampilan otak besar. Umumnya, dapat dilihat saat mereka bermain. Misalnya, saat anak-anak berlarian, melompat, meloncat. Perkembangan fisik maupun psikis anak sangat berpengaruh dalam perkembangan motorik kasar. Biasanya saat fisik dan psikis anak baik, motorik anak juga akan mengikuti. Hurlock dalam (Kusumaningtyas, 2016) menyatakan bahwa kemampuan motorik tidak hanya melalui kematangan, melainkan harus dibubuhi dengan latihan.

Seperti halnya KB Aisyiyah Jonggrangan, Klaten Utara, untuk meningkatkan sistem motorik dibuatlah permainan dengan metode yang menarik, yaitu metode Outbound. Adanya pembelajaran yang dilaksanakan di luar ruangan tentunya akan membuat siswa merasa bebas dan senang. Outbound yang dibuat dengan menyelipkan permainan-permainan tentunya akan berbeda. Hal ini dirasa dapat meningkatkan pengalaman belajar anak, terlebih lagi dapat bermanfaat untuk meningkatkan motorik anak.

\section{Simpulan}

Berdasarkan paparan hasil dan pembahasan di atas, dapat ditarik simpulan bahwa pengembangan permainan Outbound dapat meningkatkan sistem motorik anak pada usia dini atau usia prasekolah maupun taman kanak-kanak. Pertama, peningkatkan sistem motorik melalui permainan Outbound bermanfaat untuk membentuk kekuatan otot dan melatih fisik anak. Kegiatan bermain di luar ruangan atau di alam bebas ini dapat menjadi sarana belajar yang menyenangkan, sekaligus sosialisasi dan pengenalan anak terhadap lingkungan sekitar. Kedua, pengaruh permainan Outbound dalam meningkatkan sistem motorik melalui kegiatan bermain, seperti berlarian, melompat, meloncat. Tidak cukup hanya berbekal kematangan, kemampuan motorik harus dipelajari melaui latihan dengan gerakangerakan fisik. Potensi motorik kasar biasanya dikembangkan untuk melatih fungsi otot besar secara optimal.

\section{Daftar Pustaka}

Akin, Y. (2015). Pengaruh Permainan Outbound (Data Processing, Hands dan Star) terhadap Kemampuan Berpikir Kritis Siswa. Jurnal Kepelatihan Olahraga, 7(1), 44-54.

Aye, T., Oo, K. S., \& Khin, M. T. (2017). Gross motor skill development of 5-yearold Kindergarten children in Myanmar. Journal of Physical Therapy Science, (June 2016), 1772-1778.

Buchori, S., Ibrahim, M., \& Saman, A. (2016). Pengaruh Character Education Training Melalui Outbound Training untuk Peningkatan Kejujuran dan Integritas. Jurnal Psikologi Pendidikan Dan Konseling, 2(1), 12-19.

Falah, N. (2014). Efektivitas Out Bound sebagai Metode Pembelajaran (Studi pada Out Bound Mahasiswa Jurusan BKI Fakultas Dakwah Dan Komunikasi UIN Sunan Kalijaga Yogyakarta). Jurnal Hisbah, 11(1), 53-74.

Garnika, E., \& Sulastri, N. M. (2017). Pemanfaatan Kegiatan Outbond Untuk Menumbuhkan Karakter Percaya Diri 
Anak Usia Dini Eneng. Jurnal Kependidikan, 16(4), 317-321.

Hakim, A. R., \& Kumala, F. N. (2016). Pengembangan Karakter Melalui Kegiatan Outbound. Jurnal Moral Kemasyarakatan, 1(2), 173-182.

Hasnida. (2014). Analisis Kebutuhan AUD. Jakarta Timur: PT. Luximo Metro Media.

Hernandez, A. M., \& Caçola, P. (2015). Motor proficiency predicts cognitive ability in four-year-olds. European Early Childhood Education Journal, 23(4), 37-41.

Juliani, A., Mustadi, A., \& Lisnawati, I. (2020). "Make A Match Model" for Improving the Understanding of Concepts and Student Learning Results. Indonesian Journal on Learning and Advanced Education (IJOLAE), 3(1), 48-56.

Kusmiati, A. M., \& Sumarno, G. (2018). Pengaruh Permainan Tradisional terhadap Kemampuan Perseptual Motorik Anak di SDN Margawatu II Garut Kota. TEGAR: Journal of Teaching Physical Education in Elementary School, 1(2), 17-23.

Kusumaningtyas, L. E. (2016). Bermain dalam Rangka Mengembangkan Motorik pada Anak Usia Dini. Jurnal INDRIA (Jurnal Ilmiah Pendidikan PraSekolah Dan Sekolah Awal), 1(1), 47-56.

Maryatun, I. B. (2011). Pemanfaatan kegian Outbound untuk melatih kerjasama (sebagai moral behavior) anak. Yogyakarta: UNY.

Mutmainah, L. (2012). Inovasi Outbound dalam Meningkatkan Perkembangan Motorik Kasar Anak Usia Prasekolah di TK Dwi Warna Jaya Kota Surabaya. Psychiatry Nursing Journal: Jurnal Keperawatan Jiwa, 1(1), 1-10.

Pang, A. W., \& Fong, D. T.-P. (2009). Research in Sports Medicine: An Fundamental Motor Skill Proficiency of Hong Kong Children Aged 6 - 9 Years. Research in Sports Medicine, 17(3), 125-144.

Sugandi, I. (2014). Konsep Kepemimpinan Guru dalam Manajemen Kegiatan Outbound. Jurnal Ilmiah Mahasiswa Pascasarjana Administrasi Pendidikan, 2(1), 1-8.

Widodo, P., \& Lumintuarso, R. (2017). Pengembangan Model Permainan Tradisional untuk Membangun Karakter pada Siswa SD Kelas Atas. Jurnal Keolahragaan, 5(2), 183-193.

Zeng, N., Ayyub, M., Sun, H., Wen, X., Xing, P., \& Gao, Z. (2017). Effects of Pthysical Activity on Motor Skills and Cognitive Development in Early Childhood: A Systematic Revview. Biomed Research International, 2017, 1-13. 